\title{
Oxygen therapy via high flow nasal cannula in pediatric intensive care unit
}

\author{
Arzu Oto, Seher Erdoğan, Mehmet Boşnak \\ Division of Pediatric Critical Care, Department of Pediatrics, Gaziantep University Faculty of Medicine, Gaziantep, Turkey. \\ E-mail: seher70@gmail.com \\ Received: 31st May 2016, Revised: 31st August 2016, Accepted: 4th November 2016
}

SUMMARY: Oto A, Erdoğan S, Boşnak M. Oxygen therapy via high flow nasal cannula in pediatric intensive care unit. Turk J Pediatr 2016; 58: 377-382.

The aim of the present study was to assess the efficacy and safety of oxygen therapy via high flow nasal cannula in pediatric patients with acute respiratory failure.

Patients who were admitted to pediatric intensive care unit and were administered high flow nasal cannula (HFNC) therapy between January 2015 and January 2016 were enrolled. Arterial blood gas parameters, respiratory rates (RR), heart rates (HR), systolic, diastolic, and mean arterial pressures (SBP, DBP, MAP), dyspnea scores, fractional oxygen indices $\left(\mathrm{FiO}_{2}\right)$, and oxygen saturations $\left(\mathrm{SatO}_{2}\right)$ were recorded at baseline, 30 minutes, and 12 hours.

The study enrolled a total of 50 patients of whom $24(48 \%)$ were female and $26(52 \%)$ were male. Statistically significant reductions occurred in mean HR and RR values at 30 minutes and 12 hours compared to those at 0 minute $(\mathrm{p}<0.05)$. Significant increases were observed in SatO2 values at 30 minutes (p.0.001) and 12 hours (p:0.005) compared to SatO2 value at 0 minute $(\mathrm{p}<0.05)$. Similarly, there occurred significant reductions in mean $\mathrm{FiO}_{2}$ values at 30 minutes and 12 hours compared to baseline $(\mathrm{p}<0.05)$. Significant reductions occurred in mean dyspnea score at 30 minutes (p:0.001) and 12 hours ( $\mathrm{p}: 0.001)$ compared to that at 0 minute $(\mathrm{p}<0.05) . \mathrm{pH}, \mathrm{PaCO}_{2}$, $\mathrm{PaO}_{2}, \mathrm{SBP}$, and DBP values at 0 minute, 30 minutes, and 12 hours were not significantly different from one another $(p>0.05)$. No significant correlations were found between treatment failure and age at admission; mean pediatric index of mortality (PIM II), pediatric risk of mortality (PRISM), pediatric logistic organ dysfunction (PELOD) and pediatric multiple organ dysfunction score (P-MODS); and HR, RR, SatO ${ }_{2}, \mathrm{pH}, \mathrm{PaCO}_{2}, \mathrm{PaO}_{2}$, SBP, DBP, $\mathrm{MAP}, \mathrm{FiO}_{2}$ at baseline $(p>0.05)$. Therapy was successful in $40(80 \%)$ patients whereas there occurred a need for invasive ventilation in $10(20 \%)$ patients. High flow nasal oxygen therapy can be used for patients with acute severe hypoxemic respiratory failure without concurrent hypercapnia when adequate equipment and monitorization tools exist.

Key words: high-flow nasal cannula; pediatric intensive care unit; respiratory failure.

Oxygen therapy via high flow nasal cannula (HFNC) is used for hypoxemic respiratory failure, acute exacerbations of chronic obstructive pulmonary disease, prophylactically against hypoxemia following extubation, sleep apnea, and respiratory failure secondary to acute heart failure. This method has been found to increase patient comfort and tolerance, reduce respiratory work, and decrease the need for respiratory support in respiratory failure episodes secondary to etiologies.
Administration of oxygen therapy via HFNC is achieved by using an air-oxygen mixer, an active humidifier, a heated circuitry, and a special nasal cannula. HFNC therapy has been shown to increase lung compliance and to improve gas exchange. It was also found to reduce nasopharyngeal dead space and to increase intrathoracic pressure, thereby forming a low-level positive end-expiratory pressure. Because of poor mask tolerance, however, noninvasive ventilation (NIV) is sometimes 
Table I. Clinical Scores

\begin{tabular}{lcc}
\hline Score & & \\
\hline Clinical signs & 0 & 1 \\
Intercostal/sternal retractions & No & Costal \\
Thoraco-abdominal dissociation & No & Moderate \\
Nasal flaring & No & Mild \\
Expiratory groan & No & At auscultation \\
Cyanosis $\left(\mathrm{SatO}_{2}\right)$ & No $(>92 \%)$ & With air $(<92 \%)$ \\
Conscience level & Normal & Depression $/$ restlesness \\
\hline
\end{tabular}

Scores: <4, 4-6, moderate, $>6$, severe.

$\mathrm{FiO}_{2:}$ Fraction of inspired oxygen; $\mathrm{SatO}_{2:}$ Oxygen saturation

inapplicable. Another major difference between NIV and HFNC is the interface. While interfaces for NIV increase anatomical dead space, those for HFNC actually decrease dead space. Since neither inspiratory push nor expiratory pull is effective in such an open circuit, HFNC cannot actively enhance inspiratory tidal volume ${ }^{1,2}$. Since especially young infants' respiratory muscles are poor in oxidative fibers, they may develop respiratory distress more easily. HFNC preserves mucociliary function, prevents atelectasis, reduces respiratory work, and favorably affects energy consumption ${ }^{3}$.

This study aimed to determine the efficacy and safety of oxygen therapy via high flow nasal cannula in pediatric patients having acute respiratory failure.

\section{Material and Methods}

This study included patients aged between 1 month and 17 years who were admitted to our pediatric intensive care unit upon a diagnosis of acute hypoxic respiratory failure $(\mathrm{PaO} 2<55$ $\mathrm{mmHg}$ in room air) between January 2015 and January 2016. Patients with upper airway obstruction, apnea, hemodynamic instability, hypercapnic respiratory failure, contraindications for NIV, and altered consciousness were excluded from the trial. HFNC therapy was applied via a nasal cannula (Optiflow, Fisher \& Paykel Healthcare, Germany). The size of the nasal cannula was set to half of that of nostrils; humidity of inspired mixture was set at 34-37 ${ }^{\circ} \mathrm{C}$; and $\mathrm{FiO}_{2}$ was titrated to attain a $\mathrm{SatO}_{2}$ of 92-97\%. Initial flow rate was set at $2 \mathrm{~L} / \mathrm{kg} / \mathrm{min}$ for infants and $1 \mathrm{~L} / \mathrm{kg} / \mathrm{min}$ for children; it was then adjusted according to arterial blood gas checks and a change in clinical status. Arterial blood gas parameters, respiratory rates (RR), heart rates (HR), systolic, diastolic, and mean arterial pressures (SBP, DBP, MAP), dyspnea scores, fractional oxygen indices $\left(\mathrm{FiO}_{2}\right)$, and oxygen saturations $\left(\mathrm{SatO}_{2}\right)$ were recorded at 0 minute, 30 minutes, and 12 hours. A switch to invasive ventilation was made when clinical or laboratory parameters deteriorated. Treatment failure criteria were determined by withdrawal due to major complications, poor tolerance, and inability to stabilize the progression of respiratory failure requiring tracheal intubation.

$\mathrm{SatO}_{2}$ as determined by pulse oximeter through the use of Masimo technology (Radical, Datascope, Irvine, CA) at $0^{\text {th }} \mathrm{min}, 30^{\text {th }} \mathrm{min}$ and $12^{\text {th }}$ hrs. PIM II, PRISM, PELOD and P-MODS (http://www.sfar.org/scores) were used to calculate the death risk online.

Respiratory evaluation between $0^{\text {th }} \mathrm{min}$, 30 $0^{\text {th }}$ min and $12^{\text {th }}$ hrs was assessed using the Clinical Score chart (Table I). Clinical score was calculated with a synthesis of Silverman and Wood-Downes tests, which are applicable to any type of pediatric acute respiratory failure. We used the Silverman test, utilizing the evaluation of the costal and sternal retractions as the only parameter, and we included the evaluations of the level of consciousness and of cyanosis criteria of the Wood-Downes score.

\section{Statistical Analysis}

IBM SPSS Statistics 22.0 (IBM SPSS, Turkey) was used for all statistical analyses. Shapiro Wilk test was used to assess the normality of study data. Quantitative data were expressed as mean and standard deviation. The normally distributed parameters measured at $0^{\text {th }}$ minute, $30^{\text {th }}$ minute, and $12^{\text {th }}$ hour were compared with variance analysis for repeated measurements with Bonferroni correction. The parameters 
Table II. Comparison of Clinical and Blood Gas Parameters at $0^{\text {th }}$ minute, $30^{\text {th }}$ minute, and $12^{\text {th }}$ Hours

\begin{tabular}{lcccccc}
\hline & \multicolumn{2}{c}{$0^{\text {th }}$ minute } & \multicolumn{2}{c}{$30^{\text {th }}$ minute } & \multicolumn{2}{c}{$12^{\text {th }}$ hours } \\
& Min-Max & Mean \pm SD & Min-Max & Mean \pm SD & Min-Max & Mean \pm SD \\
\hline $\mathrm{HR}(/ \mathrm{min})$ & $52-195$ & $137.74 \pm 28.8$ & $76-184$ & $128.04 \pm 25.8$ & $72-174$ & $118.62 \pm 27.15$ \\
$\mathrm{RR}(/ \mathrm{min})$ & $17-80$ & $41.94 \pm 14.73$ & $20-72$ & $38.58 \pm 12.78$ & $17-64$ & $35.3 \pm 11.34$ \\
$\mathrm{SatO}_{2}$ & $70-99$ & $94.14 \pm 5.31$ & $79-100$ & $96.74 \pm 3.67$ & $78-100$ & $96.42 \pm 4.51$ \\
$\mathrm{FiO}_{2}$ (median) & $30-60$ & $39 \pm 7.82$ & $21-100$ & $51.26 \pm 16.2$ & $21-90$ & $43.32 \pm 15.01$ \\
$\mathrm{PaCO}_{2}$ & $26-133$ & $46.28 \pm 17.46$ & $24-85$ & $43.02 \pm 11.51$ & $25-81$ & $43.53 \pm 8.82$ \\
$\mathrm{PaO}_{2}$ & $50-203$ & $81.74 \pm 33.88$ & $51-135$ & $80.89 \pm 20.58$ & $50-140$ & $82.4 \pm 20.3$ \\
$\mathrm{pH}_{\mathrm{SBP}(\mathrm{mmHg})}$ & $79-136$ & $108 \pm 13.99$ & $78-139$ & $106.7 \pm 15.86$ & $81-136$ & $103.96 \pm 13.98$ \\
$\mathrm{DBP}(\mathrm{mmHg})$ & $33-98$ & $65.1 \pm 16.26$ & $35-100$ & $61.48 \pm 13.39$ & $40-108$ & $62.32 \pm 13.17$ \\
Wood-Downes & $2-12$ & $8.8 \pm 2.51$ & $2-12$ & $7.36 \pm 2.44$ & $0-11$ & $4.8 \pm 2.75$ \\
$\mathrm{score}$ & & $7.36 \pm 0.1$ & $7.03-7.52$ & $7.37 \pm 0.08$ & $7.08-7.5$ & $7.37 \pm 0.08$ \\
\hline
\end{tabular}

${ }^{1}$ Analysis of Variance in Repeated Measures ${ }^{2}$ Friedman Test ${ }^{*} p<0.05$

HR: Heart rate; RR: Respiration rate; $\mathrm{SatO}_{2}$ : Oxygen saturation; $\mathrm{FiO}_{2}$ : Fraction of inspired oxygen; $\mathrm{PaCO}_{2}$ : Partial pressure of carbon dioxide; $\mathrm{PaO}_{2}$ : Partial pressure of oxygen; SBP: Systolic blood pressure, DBP: Diastolic blood pressure

with non-normal distribution measured at $0^{\text {th }}$ minute, $30^{\text {th }}$ minute, and $12^{\text {th }}$ hour were compared with Friedman analysis; the time point causing the difference was determined with Wilcoxon signed rank test. Normally distributed parameters were compared with Student $t$ test between the two groups; nonnormally distributed parameters were compared with Mann Whitney U test. A p value of less than 0.05 was considered statistically significant.

\section{Results}

The study included a total of 50 patients of whom $24(48 \%)$ were female and 26 (52\%) were male. The mean age was $77.4 \pm 81.09$ (min.4-max.180) months; the mean HFNC administration time was $58.44 \pm 54.27$ (min.4max.240) hours; mean PIM score was 29.98 \pm 21.12 (2-94); mean PMODS score was $7.69 \pm 5.1$ (1-20); mean PRISM score was $17.33 \pm 6.75$ (6-33); and mean PELOD score was $20.3 \pm 7.32(2-32)$. The therapy was successful in $40(80 \%)$ patients while $10(20 \%)$ patients needed invasive ventilation. There was a significant difference between mean HR values at $0^{\text {th }}$ minute, 30 minutes, and 12 hours (p:0.001; $\mathrm{p}<0.05$ ). Paired analyses indicated that the statistical significance was derived from a drop of $\mathrm{HR}$ value from $0^{\text {th }}$ minute to 30 minutes (p.0.003) and 12 hours (p:0.001) $(p<0.05)$. There was also a significant reduction in mean $\mathrm{HR}$ value at 30 minutes compared to that at 12 hours (p:0.010; $\mathrm{p}<0.05)$.

Similarly, a significant reduction occurred in mean RR values at 30 minutes (p.0.032) and 12 hours (p:0.001) compared to the mean RR value at $0^{\text {th }}$ minute $(\mathrm{p}<0.05)$. A significant reduction was found in the mean $\mathrm{RR}$ at 12 hours compared to that at 30 minutes (p:0.014; $\mathrm{p}<0.05)$.

A significant increase was observed in $\mathrm{SatO}_{2}$ at 30 minutes (p.0.001) and 12 hours (p:0.005) compared to that at 0 minute $(p<0.05)$. No significant difference was found between mean $\mathrm{SatO}_{2}$ levels at 30 minutes and 12 hours (p:1.000; p>0.05).

Compared to the mean $\mathrm{FiO} 2$ at 0 minute, $\mathrm{FiO}_{2}$ values at 30 minutes and 12 hours were significantly reduced $(\mathrm{p}<0.05)$. Mean $\mathrm{FiO}_{2}$ at 12 hours was also significantly reduced compared to the mean $\mathrm{FiO}_{2}$ at 30 minutes (p:0.001; $\mathrm{p}<0.05$ ).

Mean dyspnea scores at 30 minutes (p:0.001) and 12 hours (p:0.001) were significantly reduced compared to the minute dyspnea score at $0^{\text {th }}$ minute $(\mathrm{p}<0.05)$. The mean score at 12 hours was also significantly lower than that at 30 minutes ( $\mathrm{p}: 0.001 ; \mathrm{p}<0.05$ ).

No significant differences were found between $0^{\text {th }}$ minute, $30^{\text {th }}$ minute, and $12^{\text {th }}$ hour $\mathrm{pH}$, $\mathrm{PaCO}_{2}, \mathrm{PaO}_{2}, \mathrm{SBP}$, and DBP values $(\mathrm{p}<0.05)$ (Table II).

Therapy failure was not significantly correlated 
Table III. Comparison of Age and Mean Scores by Therapy Success

\begin{tabular}{lccc}
\hline & Therapy successful & Therapy failed & \\
& Mean \pm SD (median) & Mean \pm SD (median) & $\mathrm{p}$ \\
\hline Age (months) & $73.6 \pm 72.85(48.5)$ & $92.6 \pm 111.7(38.5)$ & 10.552 \\
PIM & $29.54 \pm 21.42(23.4)$ & $31.74 \pm 20.9(27.6)$ & ${ }^{1} 0.743$ \\
PELOD & $19.38 \pm 6.91(21)$ & $24 \pm 8.11(26)$ & ${ }^{1} 0.124$ \\
PMODS & $7.52 \pm 5.57(6)$ & $8.33 \pm 2.94(9.5)$ & ${ }^{1} 0.213$ \\
PRISM & $16.79 \pm 6.49$ & $19.5 \pm 7.69$ & ${ }^{2} 0.261$ \\
\hline
\end{tabular}

${ }^{1}$ Mann Whitney-U Test ${ }^{2}$ Student $T$ Test

PIM: Pediatric index of mortality; PELOD: Pediatric logistic organ dysfunction; P-MODS: Pediatric multiple organ dysfunction score; PRISM: Pediatric risk of mortality

to age at admission, and PIM, PRISM, PMODS, and PELOD scores (Table III). Similarly, it was not significantly correlated to $\mathrm{HR}, \mathrm{RR}, \mathrm{SatO}_{2}$, $\mathrm{PaCO}_{2}, \mathrm{PaO}_{2}, \mathrm{pH}, \mathrm{SBP}, \mathrm{DBP}, \mathrm{MAP}$, and $\mathrm{FiO}_{2}$ dyspnea score at $0^{\text {th }}$ minute (Table IV).

No significant difference was found in terms of healing in $30^{\text {th }}$ minute and $12^{\text {th }}$ hour $\mathrm{FiO}_{2}$ levels between the cases of which treatments were successful and unsuccessful $(p>0.05)$. When no significant difference was found in terms of the decrease that was found in $30^{\text {th }}$ minute scores with regard to $0^{\text {th }}$ minute between the cases of which treatments were successful and unsuccessful, the decrease level in $12^{\text {th }}$ minute score in the group of which treatment was successful, was statistically more significant (p:0.004). (Table V).

\section{Discussion}

So far, multiple studies have investigated the efficacy of non-invasive ventilation in various types of acute respiratory failure (ARF) ${ }^{4-6}$. However, the experience with children is limited in this subject. NIV has been shown to favorably affect prognosis following extubation, in acute exacerbation of chronic respiratory failure, and hypoxic respiratory failure ${ }^{7,8}$.

It was reported that in pediatric patients younger than 6 months, pharyngeal pressure was increased as flow increased, and at a level of $7 \mathrm{~L} / \mathrm{min}$ the mean pressure and PEEP pressure were elevated to 4 and 6.5 $\mathrm{cmH}_{2} \mathrm{O}$, respectively ${ }^{9}$. Furthermore, when humidified and heated oxygen-air mixture was

Table IV. Comparison of Clinical and Blood Gas Parameters at Therapy Onset with Respect to Therapy Success

\begin{tabular}{lccc}
\hline 0 minute & $\begin{array}{c}\text { Therapy successful } \\
\text { Mean } \pm \text { SD }\end{array}$ & Mean \pm SD & $p$ \\
\hline $\mathrm{HR}(/ \mathrm{min})$ & $136.6 \pm 28.4$ & $142.3 \pm 31.57$ & ${ }^{1} 0.581$ \\
$\mathrm{RR}(/ \mathrm{min})$ & $42.28 \pm 15.26$ & $40.6 \pm 13.02$ & ${ }^{1} 0.751$ \\
$\mathrm{SatO}_{2}$ & $94.2 \pm 5.32$ & $93.9 \pm 5.53$ & ${ }^{1} 0.875$ \\
$\mathrm{PaCO}_{2}$ & $47.21 \pm 18.95$ & $42.59 \pm 9.15$ & ${ }^{1} 0.460$ \\
$\mathrm{PaO}_{2}$ & $80.36 \pm 34.87$ & $87.28 \pm 30.63$ & ${ }^{1} 0.569$ \\
$\mathrm{pH}$ & $7.36 \pm 0.11$ & $7.37 \pm 0.06$ & ${ }^{1} 0.613$ \\
$\mathrm{SBP}(\mathrm{mmHg})$ & $108.8 \pm 13.83$ & $104.8 \pm 14.94$ & 10.424 \\
$\mathrm{DBP}(\mathrm{mmHg})$ & $66.4 \pm 17.47$ & $59.9 \pm 8.85$ & 10.109 \\
$\mathrm{MAP}(\mathrm{mmHg})$ & $86.88 \pm 16.2$ & $80.8 \pm 10.24$ & ${ }^{1} 0.266$ \\
$\mathrm{FiO}$ (median) & $38.13 \pm 7.13$ & $42.5 \pm 9.79$ & ${ }^{2} 0.203$ \\
Wood-Downes & $8.53 \pm 2.63$ & $9.9 \pm 1.6$ & ${ }^{2} 0.138$ \\
Score (median) & & &
\end{tabular}

${ }^{1}$ Student $t$ Test ${ }^{2}$ Mann-Whitney U Test

HR: Heart rate; RR: Respiration rate; $\mathrm{SatO}_{2}$ : Oxygen saturation; $\mathrm{PaCO}_{2}$ : Partial pressure of carbon dioxide; $\mathrm{PaO}$ : $\mathrm{Partial}$ pressure of oxygen; SBP: Systolic blood pressure; DBP: Diastolic blood pressure; MAP: Mean arterial pressure; FiO ${ }_{2}$ Fraction of inspired oxygen 
Tablo V. Evaluation of the Differences that are Found in $0^{\text {th }}, 30^{\text {th }}$ and $12^{\text {th }}$ Hour Fio 2 and Score with Regard to Success of the Treatment

\begin{tabular}{|c|c|c|c|c|}
\hline & & $\begin{array}{c}\text { Therapy successful } \\
\text { Mean } \pm \text { SD }\end{array}$ & $\begin{array}{c}\text { Therapy failed } \\
\text { Mean } \pm S D\end{array}$ & $\mathrm{p}$ \\
\hline \multirow{2}{*}{$\mathrm{FiO}_{2}$} & $0^{\text {th }}-30^{\text {th }} \min$ & $12.55 \pm 13.47(9)$ & $11.10 \pm 12.92(10)$ & 0.778 \\
\hline & $0^{\text {th }} \min -12^{\text {th }}$ h & $2.90 \pm 11.62(0)$ & $10.0 \pm 12.25(10)$ & 0.111 \\
\hline \multirow{2}{*}{$\begin{array}{l}\text { Wood-Downes } \\
\text { Score }\end{array}$} & $0^{\text {th }}-30^{\text {th }} \min$ & $-1.60 \pm 1.37(-1)$ & $-0.80 \pm 0.92(-0.5)$ & 0.083 \\
\hline & $0^{\text {th }} \min -12^{\text {th }} \mathrm{h}$ & $-4.55 \pm 2.19(-4.5)$ & $-1.8 \pm 2.25(-2.5)$ & $0.004^{*}$ \\
\hline
\end{tabular}

Mann Whitney U Test $* p<0.05$

$\mathrm{FiO}_{2}$ : Fraction of inspired oxygen

administered to trachea, upper airway resistance was also reduced ${ }^{10}$. In a study published in 2011 where HFNC therapy was administered to infants, only $6(3.6 \%)$ of 166 patients with bronchiolitis required invasive ventilation ${ }^{11}$. Various studies have demonstrated that HFNC reduced the need for intubation by $8-19 \%$ in patients with acute respiratory failure ${ }^{12,13}$. In children younger than 2 years of age HFNC failure occurs within the first 7-14 hours of therapy onset whereas NIV techniques usually fail within the first 2 hours $^{14}$. The HFNC therapy failed a need for intubation emerged in $20 \%$ of patients in our study. We suggest that this resulted from the severity of our patients' clinical condition necessitating intensive care unit follow-up. In our unit, it has been detected that intubation rate was $73 \%$ in period when HFNC was not used and that it became $70 \%$ after HFNC was used.

In a prospective trial dated 2010 where the efficacy of NIV was evaluated in 47 pediatric patients with ARF, treatment failure was correlated to younger age and the need of $>0.60 \mathrm{~cm} \mathrm{H}_{2} \mathrm{O} \mathrm{FiO}_{2}$; intubation was required in $9(19.1 \%)$ of 47 patients in that study 15 . We did not detect any correlation between treatment failure and age or $\mathrm{FiO}_{2}$ requirement.

Lenglet et al. ${ }^{16}$ reported that when HFNC respiratory rate fell from 28 breath/min to 25 breath $/ \mathrm{min}, \mathrm{SpO}_{2}$ rose from $90 \%$ to $97 \%$ $(p<0.001)$, and this method was well tolerated without any side effects. Similarly, Mayfield et al. ${ }^{17}$ reported that heart rate fell from $158 \mathrm{bpm}$ to $144 \mathrm{bpm}$ in the HFNC responders whereas it rose from $159 \mathrm{bpm}$ to $162 \mathrm{bpm}$ in HFNC non-responders $(p=0.02)$. Our study similarly demonstrated a drop in heart rate with HFNC, so that HR fell from $137 \mathrm{bpm}$ at baseline to
$128 \mathrm{bpm}$ at 30 minutes and $118 \mathrm{bpm}$ at 12 hours. Likewise, RR was reduced to $38 / \mathrm{min}$ at 30 minutes and $35 / \mathrm{min}$ at 12 hours from $41 / \mathrm{min}$ at baseline. Mean dyspnea score was also reduced from 8 at baseline to 7 at 30 minutes and 4 at 12 hours.

Frat et al. ${ }^{18}$ investigated the clinical outcomes of high flow nasal oxygen therapy, noninvasive ventilation, and standard oxygen therapy via mask in 310 intensive care unit patients with non-hypercapnic acute respiratory failure. They showed that high flow nasal oxygen therapy led to a non-significant reduction in the frequency of endotracheal intubation compared to other treatment methods. In a postHoc analysis of 238 patients having severe hypoxemia $\left(\mathrm{PaO}_{2} /\right.$ $\mathrm{FiO}_{2} \leq 200 \mathrm{mmHg}$ ) at baseline, intubation rate was significantly lower in the high flow nasal oxygen group than the other groups $(\mathrm{p}=0.009)$. Furthermore, high flow nasal oxygen therapy increased the number of ventilator-free days, reduced 90-day mortality compared to the other two groups, and enhanced patient comfort.

Abboud et al. ${ }^{19}$, in a study comprising 113 patients who received HFNC therapy, reported that patients that necessitated intubation during follow-up had a greater number of breath per minute, a higher $\mathrm{PaCO}_{2}$ level, and had more criteria for pediatric mortality risk. In another study it was reported that patients whose tachycardia did not regress at 60 and 90 minutes needed intubation ${ }^{20}$. We did not find any correlation between treatment failure and initial blood gas parameters, Silverman and Wood-Downes score, $\mathrm{FiO}_{2}$ need, $\mathrm{HR}$, and $\mathrm{RR}$. We think that this situation stems from inadequacy of the parameters used, which is one of the weak points of the study.

Three cases of pneumothorax and 
pneumomediastinum that developed during HFNC application have been reported ${ }^{21}$. Air leak syndromes in this application may result from the use of inappropriate prongs obstructing the nostril lumen. According to some authors, other risks associated with HFNC application include a greater need for invasive treatment and higher mortality and morbidity risk in cases with respiratory decompensation ${ }^{22}$. No side effects such as pneumothorax, bradycardia, and bradypnea, or a need for cardiopulmonary resuscitation were observed in any of the patients during the administration of HFNC. High flow nasal oxygen therapy can be used for patients with acute severe hypoxemic respiratory failure without concurrent hypercapnia when adequate equipment and monitorization tools exist.

\section{REFERENCES}

1. Wilkinson DJ, Andersen CC, Smith K, Holberton J. Pharyngeal pressure with high-flow nasal cannulae in premature infants. J Perinatal 2008; 28: 42-47.

2. Pham TM, O'Malley L, Mayfield S, Martin S, Schibler A. The effect of high flow nasal cannula therapy on the work of breathing in infants with bronchiolitis. Pediatr Pulmonol 2014; 50: 713-720.

3. Rubin S, Ghuman A, Deakers T, Khemani R, Ross P, Newth CJ. Effort of breathing in children receiving high-flow nasal cannula. Pediatr Crit Care Med 2014; 15: $1-6$.

4. Girou E, Schortgen F, Delclaux C, et al. Association of noninvasive ventilation with nosocomial infections and survival in critically ill patients. JAMA 2000; 284 : 2361-2367.

5. Peter JV, Moran JL, Phillips-Hughes J, et al. Noninvasive ventilation in acute respiratory failure--A meta-analysis update. Crit Care Med 2002; 30: 555-562.

6. Keenan SP, Sinuff T, Cook DJ, et al. Does noninvasive positive pressure ventilation improve in acute hypoxemic respiratory failure? A systematic review. Crit Care Med 2004; 32: 2516-2523.

7. Ottonello G, Villa G, Doglio L, et al. Noninvasive ventilation with positive airway pressure in paediatric intensive care. Minerva Pediatr 2007; 59: 85-89.

8. Mayordomo-Colunga J, Medina A, Rey C, et al. Predictive factors of non invasive ventilation failure in critically ill children: a prospective epidemiological study. Intensive Care Med 2009; 35: 527-536.
9. Milesi C, Boubal M, Jacquot A, et al. High-flow nasal cannula: recommendations for daily practice in pediatrics. Ann Intensive Care 2014; 4: 29.

10. Dysart K, Miller TL, Wolfson MR, Shaffer TH. Research in high flow therapy; mechanism of action. Respir Med 2009; 103: 1400-1405.

11. Schibler A, Pham TM, Dunster KR, et al. Reduced intubation rates for infants after introduction of highflow nasal prong oxygen delivery. Intensive Care Med 2011; 37: 847-852.

12. Kelly GS, Simon HK, Sturm JJ. High-flow nasal cannula use in children with respiratory distress in the emergency department: predicting the need for subsequent intubation. Pediatr Emerg Care 2013; 29: 888-892.

13. Spentzas T, Minarik M, Patters AB, Vinson B, Stidham G. Children with respiratory distress treated with high-flow nasal cannula. Intensive Care Med 2009; 24: 323-328.

14. Essouri S, Chevret L, Durand P, Haas V, Fauroux B, Devictor D. Noninvasive positive pressure ventilation: five years of experience in a pediatric intensive care unit. Pediatr Crit Care Med 2006; 7: 329-334.

15. Mc Kiernan C, Chua LC, Visintainer PF, Allen H. High flow nasal cannulae therapy in infants with bronchiolitis. J Pediatr 2010; 156: 634-638.

16. Lenglet H, Sztrymf B, Leroy C, Brun P, Dreyfuss D, Ricard JD. Humidified high flow nasal oxygen during respiratory failure in the emergency department: feasibility and efficacy. Respir Care 2012; 57: 1873 1878.

17. Mayfield S, Bogossian F, O'Malley L, Schibler A. High flow nasal cannula oxygen therapy for infants with bronchiolitis: pilot study. J Pediatr Child Health 2014; 50: $373-378$

18. Frat JP, Thille AW, Mercat A, et al. High-flow oxygen through nasal cannula in acute hypoxemic respiratory failure. N Engl J Med 2015; 372: 2185-2196.

19. Abboud PA, Roth PJ, Skiles JL, Stolfi A, Rowin ME. Predictors of failure in infants with viral bronshiolitis treated with high-flow, high-humidity nasal cannula therapy. Pediatr Crit Care Med 2012; 13: 343-349.

20. Mckiernan C, Chua LC, Visinyainer PF, Allen H. High flow nasal cannulae therapy in infants with bronchiolitis. J Pediatr 2010; 156: 634-638.

21. Hegde S, Prodhan P. Serious air leak syndrome complicating high flow nasal cannula therapy: a report of 3 cases. Pediatrics 2013; 131: e939-944.

22. Carrillo A, Gonzalez-Diaz G, Ferrer M, MartinezQintana ME, Lopez-Martinez A, Llamas N, et al. Noninvasive ventilation in community-acquired pneumonia and severe acute respiratory failure. Intensive Care Med 2012; 38: 458-466. 